\title{
Effect of chemical treatments used for dormancy breaking on the number of stems and tubers of Hungarian potato varieties
}

\section{Ádám ESZTERGÁLYOS (D) 1, Zsolt POLGÁR (D) 1,2*}

\author{
${ }^{1}$ Potato Research Centre, University of Pannonia, Deák Ferenc Str. 16., H-8360 Keszthely, Hungary \\ 2 University of Kaposvár, Faculty of Agricultural and Environmental Sciences, Guba Sándor Str. 40., H- \\ 7400 Kaposvár, Hungary
}

\begin{abstract}
The length of tuber dormancy of potato varieties is an important factor in the profitability of the potato sector. Under temperate climatic conditions longer dormancy is more advantageous. However, in case of multiple planting within one growing season, in seed multiplication programs or during rapid post-harvest disease testing, breaking or shortening of dormancy is often needed. Numerous ways for chemical regulation of dormancy period were developed, but the efficiency of such methods is strongly genotype dependent. Recently a comparative study of chemical treatments for breaking tuber dormancy of some new Hungarian potato varieties was carried out. Continuing this work, here we report about the effects of chemical treatments used for breaking dormancy on the number of stems and tubers of progeny plants. The experiment was conducted in three consecutive vegetation period, with three varieties having different maturity type and different dormancy period: Balatoni rózsa, Botond and Démon. Treatments were performed using gibberellic-acid, benzyl-adenine and Rindite in different concentrations and combinations. After the dormancy period, tubers were planted into pots and grown under controlled conditions. Number of developed stems and tubers was counted. According to the results, applied treatments had a large effect on the number of developing stems and tubers of the progeny plants. Combined treatments of Rindite+gibberellic-acid, and gibberellic-acid at 100 ppm increased significantly the number of stems and tubers. Correlation between the efficiency of dormancy breaking and the number of developed tubers was found. Based on our data, Rindite and gibberellic-acid have an important role not only in breaking dormancy, but also in increasing the tuber number/plant. This positive effect could be utilized in seed potato production.
\end{abstract}

Keywords: Solanum tuberosum, sprouting, tuber set/plant, Rindite, gibberellic-acid

\section{INTRODUCTION}

One of the most popular ways to start seed potato (Solanum tuberosum L.) production is to propagate PBTC (Pre-Basic Tissue Culture) mini-tubers in greenhouses, produced from in vitro plantlets. Mini-tuber production creates a bridge between the rapid in vitro multiplication, based on nodal cuttings and the field multiplication of seed tubers (Struik and Lommen, 1999). In vitro propagated potato plantlets set tubers within a short time, but these are not readily suitable for further propagation right after harvest. Freshly harvested tubers are dormant, and they cannot sprout even under optimal environmental conditions for sprouting (Van Ittersum, 1992). This phenomenon is called deep or

*CORRESPONDING AUTHOR:

Kaposvár University

$\triangle$ H-7400 Kaposvár, Guba S. str. 40., 皿 +36-82-505-800

E-mail: zsolt.polgar@hotmail.com 
internal dormancy and biochemically regulated by plant hormones (Coleman et al., 2001; Suttle, 2004; Benkeblia et al., 2008; Askenova et al., 2013).

There are significant differences between potato varieties in the duration of internal dormancy, which is partly related to their maturity type. Varieties having shorter season, early maturity type have usually shorter dormancy, while varieties having longer vegetation period have longer dormancy. Moreover, environmental factors like the amount of temperature collected by the plants during the growing season, the day length (Wiersema, 1985; Tor, 2011; Askenova et al., 2012; Tiemens et al., 2013), the abiotic stresses, e.g. heat shock and periodic water deficiency (Burton, 1989; Ezekiel and Singh, 2003; Zarzyńska, 2004; Muthoni et al., 2014) and tuber size (Suttle, 2007; Hassani et al., 2014) also has influence on the length of dormancy. However, the duration of tuber dormancy depends primarily on the genotype (Beukema and Zaag, 1979; Zarzyńska, 2004; Hassani et al., 2014; Bamberg, 2010; Nasiruddin et al., 2016; Wróbel et al., 2017).

The ability to regulate dormancy is essential for the potato sector. Delayed sprouting (long dormancy) is desired during the need for long-term storage. Usually this can be achieved by storage tubers at low temperature $\left(2-4^{\circ} \mathrm{C}\right)$ or treatments by synthetic sprouting inhibitors (Wiltshire and Cobb, 1996; Struik and Wiersema, 1999; Tor, 2011). Under temperate climatic conditions longer dormancy is more advantageous, while in Mediterranean or subtropical conditions, where repeated planting within one growing season or even permanent planting is possible, shorter dormancy is preferred (Struik and Lommen, 1999). In seed tuber propagation programs it can be necessary to replant tubers after harvest as fast as possible to shorten propagation cycle. The rapid post-harvest disease testing protocols also require the breaking of dormancy, which can be executed by chemical treatments or plant hormones (Coleman, 1983; Struik and Wiersema, 1999; Suttle, 2004, Wróbel, 2008).

During the last decades numerous ways to regulate dormancy duration were developed. For example: treating tubers with gibberellic-acid (GA) (Struik and Wiersema, 1999; Hartmann et al., 2011; Hassani et al., 2014; Nasiruddin et al., 2016; Wróbel et al., 2017); Rindite, and combinations with GA (Bryan, 1989); benzyl-adenine (BA) (Suttle, 2004; Majeed and Bano, 2006); bromoethane (Coleman, 1983; Alexopoulos et al., 2009); or thiourea (Hosseini et al., 2011; Hassani et al., 2014). However, the efficiency of these methods are strongly genotype dependent (Struik and Wiersema, 1999; Majeed and Bano, 2006; Suttle, 2008; Hosseini et al., 2011; Hassani et al., 2014; Nasiruddin et al., 2016; Wróbel et al., 2017). Moreover, there are a few publications about the side effects of treatments on later sprout development and tuber setting of 
progeny plants (Majeed and Bano, 2006; Askenova et al., 2012; Hassani et al., 2014; Wróbel et al., 2017), and these results are limited to a few varieties only.

The biochemical mechanism of external treatments is partially known. Dormancy and sprout development are regulated by the interaction of major plant growth regulators, primarily by the ratio of GA and abscisic-acid (ABA) (Carli et al., 2016). Treatments control the relative concentrations of growth promoters and inhibitors that trigger sprout formation (Hemberg, 1985). Some treatments may regulate the physiological age of the tuber, while others may inhibit apical dominance and thus increase sprouting of lateral axillary buds (Askenova et al., 2013; Carli et al., 2016). This may affect further sprout/stem development and indirectly the number of tubers (Suttle, 2004; Benkeblia et al., 2008). The role of GA in breaking dormancy has been identified (Fernie and Willmitzer, 2001). Studies have reported that external GA treatment promote sprouting and increase the number of sprouts per tuber. However, higher concentrations result elongated stems, morphologically abnormal plants and deformed tubers (Choudhuri and Ghose, 1963; Bryan, 1989; Struik and Wiersema, 1999; Suttle, 2004). On the other hand, indole-acetic-acid (IAA) also plays a significant role in germination. It has been hypothesized that IAA controls apical dominance by inhibiting lateral bud sprouting (Pavlista, 2004). In case of treated tubers apical bud sprouts first. Planting tubers in apical dominance stage often results single stem plants and hence reduced yield. Chemical treatments can affect apical dominance and thus yield as well. They can promote additional sprouts develop and the multiple sprouting. This is the optimum stage to planting, resulting plants with several stems, stolons and tubers. (Muthoni et al., 2014).

In our case a comparative study was carried out to test the effect of different dormancy breaking methods on some new Hungarian potato varieties (results are under publication). Continuing this study, we evaluated the effect of these treatments on stem and tuber number of progeny plants.

\section{MATERIALS AND METHODS}

The experiment was conducted in the Storage Physiology Laboratory of the Potato Research Centre, University of Pannonia, Centre for Agricultural Sciences at Keszthely, with two early maturing varieties, Balatoni rózsa and Botond, and a medium-early maturing variety, Démon. The experiment was set up in three consecutive vegetation period, in the fall of 2016, 2017 and 2018. Superelite (Pre Basic 2) class seed tubers which are uniform in size were used of each variety in each year. 
The following treatments were applied: soaking tubers in aqueous solution of GA, concentrations of 10, 50 and 100 ppm for 1 hour (Bryan, 1989); tubers soaked in the aqueous solution of BA, concentrations of 20,30 and $100 \mathrm{ppm}$ for 1 day (Suttle, 2004); tubers treated by Rindite (7-3-1 mixture of ethylenechlorohydrin, ethylene dichloride and carbon tetrachloride) for 2 days. In addition, a combined Rindite+GA100 ppm treatment (Combined) was also used (for 2 days Rindite and for 1 hour GA100) (Bryan, 1989). The dormancy period was determined according to the method of Carli et al. (2016).

After examining the dormancy period, 12-12 sprouting tubers were randomly selected per treatment. The experiment was carried out in 3 replications with 4 tubers in each replicate. The tubers were planted individually in 3 -liter pots filled with peat substrate. The plants were grown under controlled conditions at constant air temperature of $22^{\circ} \mathrm{C}$ and $85 \%$ relative humidity (RH $\%$ ) in growth chamber until biological maturity. The amount of irrigation water was $30 \mathrm{~mm} /$ week, which was used to supplement the nutrients according to the growing practice. A 16-hour light period (5-21h) was used. For illumination Osram oH054W/840 lumilux cool white fluorescent lamp was used. The number of developing stems was recorded on the 20th day after planting. After biological maturation, peat was drained from the pots and the number of tubers was counted. Data were prepared and sorted using Microsoft Office 2007, for statistical analysis IBM SPSS 22 software was used.

\section{RESULTS}

Treatments of Rindite, GA100, GA50 and Combined significantly reduced the dormancy period for all three varieties in all growing season (Figure 1), according to Duncan-test ( $p$-value $\leq 0.05$ ). However, GA at 10 ppm concentrations (GA10) did not reduced it in each cases significantly in 2018. BA treatments were significantly less effective compared to the other treatments. In absolute terms, based on the average treatment efficiency, chemical treatments reduced the dormancy of Balatoni rózsa the most (in average by 33\% compared to control). They had the smallest impact on the dormancy of Démon (average reduction is $25 \%$ ). Botond and Démon responded similarly to the treatments in each year, but the reaction of Balatoni rózsa differed in each year. The effect of Rindite and Combined treatments was extremely high in 2017 and 2018 for this variety. 


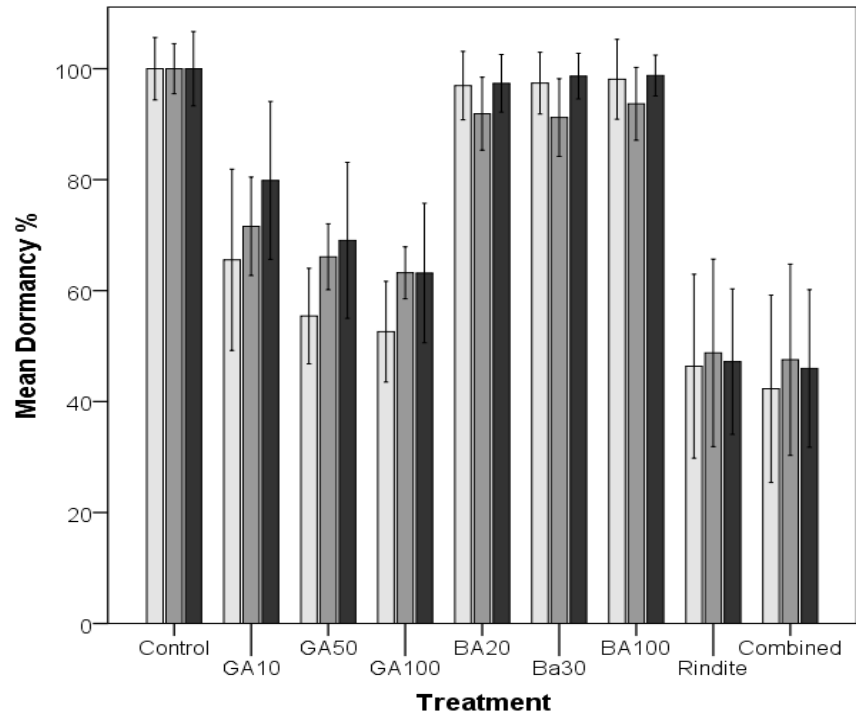

Variety

$\square$ Balatoni rózsa

Botond

Démon

Error Bars: +/- $1 \mathrm{SD}$

Figure 1

The effect of treatments on the tuber dormancy of the investigated cultivars. (Results are expressed as an average percentage of the control treatment. Data comprises the mean values of the three year)

To determine the effect of the treatments on plant development, the stem number of the emerged plants was recorded on the $20^{\text {th }}$ day after planting, and the number of tubers was counted after plants matured. The results are illustrated in Figure 2. According to the Duncan test ( $\mathrm{p} \leq 0.05$ ), GA50, GA100, Rindite and Combined treatments significantly increased both the number of stems and tubers (Table 1). GA100 and Combined were the most effective treatments for increasing the number of stems and tubers. GA100 increased the stems to an average of $204.1 \%$ and the number of tubers to $259.9 \%$. While Combined treatment increased stems to an average of $209.5 \%$ and number of tubers to $268.0 \%$, compared to the control. GA10 and BA treatments did not increase the number of stems and tubers compared to control. We found a moderately strong correlation between the change of the tuber number and the stem number due to the treatments $(r=0.572$, Pearson correlation is significant at the 0.01 level). 


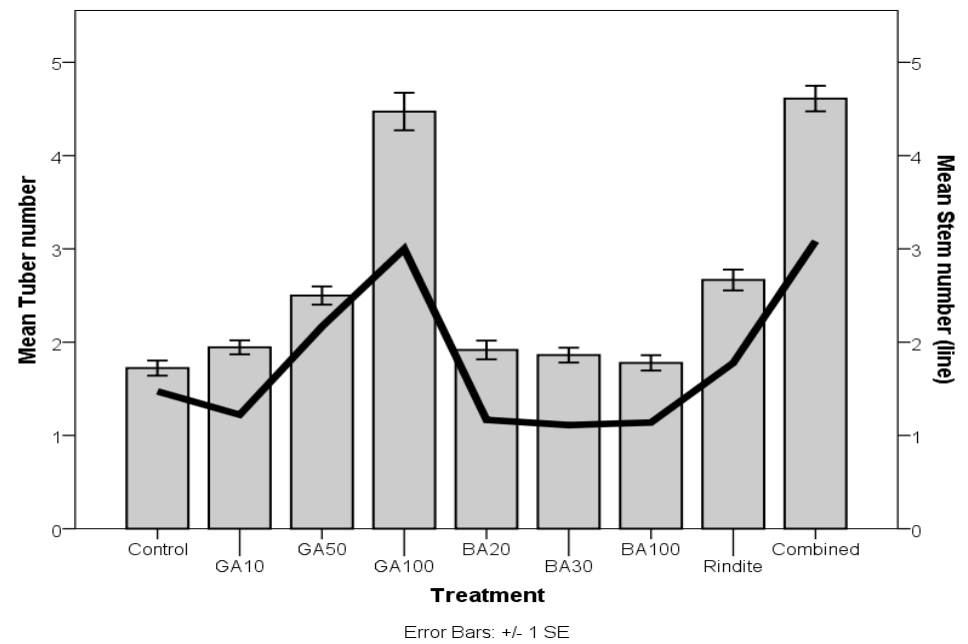

Figure 2

Effect of chemical treatments on the average stem and tuber number of the investigated varieties. (Results are averages of all years and varieties. The columns show the tuber number and the line the stem number)

Overall, GA100 and Combined treatments resulted the most stems and tubers. GA10 and BA treatments did not cause significant differences in increasing of stem and tuber number in any years compared to control. The results are discussed in details as follows.

\section{Table 1}

The effect of chemical treatments on the stem and tuber number of investigated cultivars

\begin{tabular}{lll}
\hline Treatment & Stem & Tuber \\
\hline Control & $1.47 \mathrm{~b}$ & $1.72 \mathrm{a}$ \\
GA10 & $1.22 \mathrm{ab}$ & $1.94 \mathrm{a}$ \\
GA50 & $\mathbf{2 . 1 7} \mathbf{~ d ~}$ & $\mathbf{2 . 5 0} \mathbf{b}$ \\
GA100 & $3.00 \mathrm{e}$ & $\mathbf{4 . 4 7} \mathrm{c}$ \\
BA20 & $1.17 \mathrm{a}$ & $1.92 \mathrm{a}$ \\
BA30 & $1.11 \mathrm{a}$ & $1.86 \mathrm{a}$ \\
BA100 & $1.14 \mathrm{a}$ & $1.78 \mathrm{a}$ \\
Rindite & $\mathbf{1 . 7 8} \mathrm{c}$ & $\mathbf{2 . 6 7} \mathbf{b}$ \\
Combined & $\mathbf{3 . 0 8} \mathbf{e}$ & $\mathbf{4 . 6 1 \mathrm { c }}$ \\
\hline
\end{tabular}

The same letters within each column mean that data do not differ significantly at $p$-value $\leq 0.05$. The bold numbers show the most effective treatments. Results are expressed as numbers of stems and tubers. The results are averages for all years and varieties 
Table 2

The effect of chemical treatments on the stem number of investigated cultivars

\begin{tabular}{|c|c|c|c|c|c|c|c|c|c|}
\hline \multirow{2}{*}{ Treatment } & \multicolumn{2}{|c|}{2016} & \multicolumn{4}{|c|}{2017} & \multicolumn{2}{|c|}{2018} & \multirow[b]{2}{*}{ Démon } \\
\hline & B. rózsa & Botond & Démon & B. rózsa & Botond & Démon & B. rózsa & Botond & \\
\hline Control & $1.25 \mathrm{ab}$ & $1.25 \mathrm{a}$ & $1.25 \mathrm{a}$ & $1.50 \mathrm{a}$ & $1.50 \mathrm{ab}$ & $3.00 \mathrm{~b}$ & $1.00 \mathrm{a}$ & $1.50 \mathrm{~b}$ & $1.00 \mathrm{a}$ \\
\hline GA10 & $1.00 \mathrm{a}$ & $1.50 \mathrm{a}$ & $1.00 \mathrm{a}$ & $1.00 \mathrm{a}$ & $2.00 \mathrm{~b}$ & $1.00 \mathrm{a}$ & $1.00 \mathrm{a}$ & $1.50 \mathrm{~b}$ & $1.00 \mathrm{a}$ \\
\hline GA50 & $1.50 \mathrm{~b}$ & $4.50 \mathrm{c}$ & $1.00 \mathrm{a}$ & $1.50 \mathrm{a}$ & $4.00 \mathrm{c}$ & $1.00 \mathrm{a}$ & $2.50 \mathrm{c}$ & $2.00 \mathrm{c}$ & $1.50 \mathrm{~b}$ \\
\hline GA100 & $1.25 \mathrm{ab}$ & $3.75 \mathrm{c}$ & $1.00 \mathrm{a}$ & $4.50 \mathrm{~b}$ & $4.50 \mathrm{~d}$ & $4.50 \mathrm{c}$ & $3.00 \mathrm{~d}$ & $2.00 \mathrm{c}$ & $2.50 \mathrm{~d}$ \\
\hline BA20 & $1.25 \mathrm{ab}$ & $1.25 \mathrm{a}$ & $1.00 \mathrm{a}$ & $1.00 \mathrm{a}$ & $1.00 \mathrm{a}$ & $1.50 \mathrm{a}$ & $1.50 \mathrm{~b}$ & $1.00 \mathrm{a}$ & $1.00 \mathrm{a}$ \\
\hline BA30 & $1.00 \mathrm{a}$ & $1.50 \mathrm{a}$ & $1.00 \mathrm{a}$ & $1.00 \mathrm{a}$ & $1.00 \mathrm{a}$ & $1.50 \mathrm{a}$ & $1.00 \mathrm{a}$ & $1.00 \mathrm{a}$ & $1.00 \mathrm{a}$ \\
\hline BA100 & $1.00 \mathrm{a}$ & $1.50 \mathrm{a}$ & $1.25 \mathrm{a}$ & $1.00 \mathrm{a}$ & $1.50 \mathrm{ab}$ & $1.00 \mathrm{a}$ & $1.00 \mathrm{a}$ & $1.00 \mathrm{a}$ & $1.00 \mathrm{a}$ \\
\hline Rindite & $1.50 \mathrm{~b}$ & $2.75 \mathrm{~b}$ & $1.75 \mathrm{~b}$ & $1.00 \mathrm{a}$ & $1.00 \mathrm{a}$ & $1.50 \mathrm{a}$ & $2.50 \mathrm{c}$ & $2.00 \mathrm{c}$ & $2.00 \mathrm{c}$ \\
\hline Combined & $3.00 \mathrm{c}$ & $4.50 \mathrm{c}$ & $2.25 \mathrm{c}$ & $5.50 \mathrm{c}$ & $2.00 \mathrm{~b}$ & $3.00 \mathrm{~b}$ & $3.00 \mathrm{~d}$ & $2.50 \mathrm{~d}$ & $2.00 \mathrm{c}$ \\
\hline
\end{tabular}

The same letters within each column mean that data do not differ at $p$-value $\leq 0.05$. The bold numbers show the most effective treatments. Results are expressed as numbers of stems

\section{Stem number}

In 2016 the stem number of all three varieties was influenced differently by the treatments (Figure 3). In that year, Botond was the most sensitive to treatments, while the Balatoni rózsa was the least affected (Table 2). However, in absolute terms, the stem number of Démon was the least modified by the treatments. Combined treatment was the most effective for all the varieties, resulting significantly more stems (in average $260 \%$ ). In case of Balatoni rózsa only this treatment resulted in significant difference compared to the other treatments $(240 \%$ of the control). In case of Botond, Combined (360\%), GA50 (360\%) and GA100 (300\%) treatments resulted significantly more stems. Treatment with Rindite greatly increased the number of stems in this variety also, to $220 \%$. For Démon, the Combined treatment was the most effective (180\%), followed by Rindite (140\%). The effect of these two treatments was statistically significant.

In 2017, the varieties responded differently to the treatments compared to the previous year. GA100 treatment significantly increased the stem number of all varieties to an average of $250 \%$. According to the Duncan test, Botond was more sensitive to the treatments than Démon and Balatoni rózsa. In absolute terms the treatments influenced the stem number of Balatoni rózsa the most. For Balatoni rózsa, Combined was the most effective treatment (367\%), followed by GA100 (300\%). The other treatments did not produce a significant difference compared to the control. For Botond, GA100 was the most efficient (300\%), followed by GA50 (267\%). For Démon, only GA100 resulted significantly more stems than the control, to $150 \%$. 
In 2018, varieties responded to treatments with altering stem number compared to previous years. GA100, Combined, Rindite and GA50 treatments effectively increased the stem number, reaching 228\%, 222\%, 194\%, and $178 \%$ increase, respectively, compared to the control. Balatoni rózsa was the most sensitive to the treatments, while stems of Botond were the least affected. In case of Balatoni rózsa, GA100 and Combined treatments increased the stem number to $300 \%$, while GA50 and Rindite to $250 \%$, all significant. For Botond we detected $67 \%$ increase caused by Combined and 33\% increase by GA100, GA50 and Rindite. For Démon, GA100 resulted 2.5 times more stem, followed by Rindite and Combined treatment, where the increase was 2.0 times more.

\section{Tuber number}

Treatments changed the total number of tubers/plant (Figure 3). The results are consequent compared to the changes in stem number (Table 3). Each year for all varieties, Combined and GA100 treatments were the most effective, inducing significantly higher tuber numbers.

In 2016, Combined treatment was the most effective for all three varieties. This treatment greatly increased the tuber number in average to $379 \% \mathrm{com}$ pared to the control. According to the Duncan test, Botond was the most sensitive to the treatments, while Démon was the least affected. In absolute terms, the tuber number of Balatoni rózsa changed the most, which was significantly increased by the Combined and GA100 treatments, to $450 \%$ and $300 \%$, respectively compared to the control. Combined treatment increased Botond's tuber number the most (to 343\%), followed by GA100 (to 314\%), with significant increasing in both cases compared to control. For Démon, Combined treatment resulted the most tubers (by 243\% more than control), followed by GA100 and Rindite, which also significantly increased the tuber number to $186 \%$ compared to control.

In 2017, we observed a similar trend, but this year GA100 treatment increased tuber numbers more than Combined treatment. This treatment resulted significantly more tubers for all varieties compared to the control, increasing it to an average of $322 \%$. According to the Duncan test, Balatoni rózsa was the most sensitive to the treatments, but in absolute terms, the tuber number of Botond changed the most. For Balatoni rózsa, GA100 treatment increased the tuber number significantly by $100 \%$ compared to the control, followed by Combined treatment (33\%). For Botond, GA100 was also the most effective treatment ( $567 \%$ vs. control), followed by Combined (233\%), significant in both cases. In the case of Démon, a similar tendency was observed to 
Botond, with a smaller treatment effect (200\% for GA100 and $175 \%$ for Combined). The Combined treatment did not significantly increase the stem number, it effectively increased the tuber numbers.

In 2018, we observed a similar trend as in 2016. Combined treatment increased the number of tubers the most, with an average increase to $336 \%$. The increase was significant for all three varieties. GA100 treatment increased the tuber number greatly and significantly $(231 \%)$ too. This year Rindite treatment was also effective (to $264 \%$ increase compared to control), similar to the effect found for stem number. Variety Botond was to be the most sensitive this year. Treatments affected the tuber number of Balatoni rózsa the least. In case of this variety the Combined treatment resulted in highest tuber number. The increase reached to $225 \%$ compared to the control, followed by GA100 and Rindite with $175 \%$. For Botond, Combined treatment was the most effective also (450\%), followed by Rindite (350\%), and then by GA100 (250\%). For Démon, also Combined treatment caused the highest increase in tuber number (333\%), followed by Rindite and GA100 (267\%), and then by GA50 (233\%). The increase was significant in all the cases.

Table 3

The effect of chemical treatments on the number of tubers/plant of the investigated cultivars

\begin{tabular}{|c|c|c|c|c|c|c|c|c|c|}
\hline \multirow{2}{*}{ Treatment } & \multicolumn{2}{|c|}{2016} & \multicolumn{4}{|c|}{2017} & \multicolumn{2}{|c|}{2018} & \multirow[b]{2}{*}{ Démon } \\
\hline & B. rózsa & Botond & Démon & B. rózsa & Botond & Démon & B. rózsa & Botond & \\
\hline Control & $1.00 \mathrm{a}$ & $1.75 \mathrm{a}$ & $1.75 \mathrm{a}$ & $3.00 \mathrm{de}$ & $1.50 \mathrm{~b}$ & $2.00 \mathrm{~b}$ & $2.00 \mathrm{ab}$ & $1.00 \mathrm{a}$ & $1.50 \mathrm{a}$ \\
\hline GA10 & $1.00 \mathrm{a}$ & $2.00 \mathrm{a}$ & $3.00 \mathrm{bc}$ & $1.50 \mathrm{ab}$ & $1.50 \mathrm{~b}$ & $2.50 \mathrm{c}$ & $2.00 \mathrm{ab}$ & $1.50 \mathrm{~b}$ & $2.50 \mathrm{c}$ \\
\hline GA50 & $1.00 \mathrm{a}$ & $3.75 \mathrm{~b}$ & $2.25 \mathrm{ab}$ & $2.50 \mathrm{~cd}$ & $2.50 \mathrm{c}$ & $2.50 \mathrm{c}$ & $2.50 \mathrm{~b}$ & $2.00 \mathrm{c}$ & $3.50 \mathrm{~d}$ \\
\hline GA100 & $3.00 \mathrm{c}$ & $5.50 \mathrm{c}$ & $3.25 \mathrm{c}$ & $6.00 \mathrm{~g}$ & $8.50 \mathrm{e}$ & $4.00 \mathrm{e}$ & $3.50 \mathrm{c}$ & $2.50 \mathrm{~d}$ & $4.00 \mathrm{e}$ \\
\hline BA20 & $1.50 \mathrm{ab}$ & $2.00 \mathrm{a}$ & $1.75 \mathrm{a}$ & 3.50 ef & $2.50 \mathrm{c}$ & $2.00 \mathrm{~b}$ & $1.50 \mathrm{a}$ & $1.00 \mathrm{a}$ & $1.50 \mathrm{a}$ \\
\hline BA30 & $1.50 \mathrm{ab}$ & $1.75 \mathrm{a}$ & $1.50 \mathrm{a}$ & $2.50 \mathrm{~cd}$ & $2.00 \mathrm{c}$ & $1.50 \mathrm{a}$ & $2.50 \mathrm{~b}$ & $1.50 \mathrm{~b}$ & $2.00 \mathrm{~b}$ \\
\hline BA100 & $2.00 \mathrm{~b}$ & $2.75 \mathrm{ab}$ & $1.75 \mathrm{a}$ & $2.00 \mathrm{bc}$ & $1.00 \mathrm{a}$ & $1.50 \mathrm{a}$ & $1.50 \mathrm{a}$ & $1.00 \mathrm{a}$ & $2.50 \mathrm{c}$ \\
\hline Rindite & $1.50 \mathrm{ab}$ & $2.25 \mathrm{a}$ & $3.25 \mathrm{c}$ & $1.00 \mathrm{a}$ & $2.50 \mathrm{c}$ & $2.50 \mathrm{c}$ & $3.50 \mathrm{c}$ & $3.50 \mathrm{e}$ & $4.00 \mathrm{e}$ \\
\hline Combined & $4.50 \mathrm{~d}$ & $6.00 \mathrm{c}$ & $6.00 \mathrm{~d}$ & $4.00 \mathrm{f}$ & $3.50 \mathrm{~d}$ & $3.50 \mathrm{~d}$ & $4.50 \mathrm{~d}$ & $4.50 \mathrm{f}$ & $5.00 \mathrm{f}$ \\
\hline
\end{tabular}

The same letters within each column mean that data do not differ significantly according to the Duncan test ( $p$-value $\leq 0.05$ ). The bold numbers show the most effective treatments. Results are expressed as numbers of tubers

As a result of treatments, we observed significant differences in the intensity of sprout development of plants within the same variety. Higher, fastergrowing plants developed from tubers that elapsed their dormancy period sooner. However, these differences evened out before flowering. 


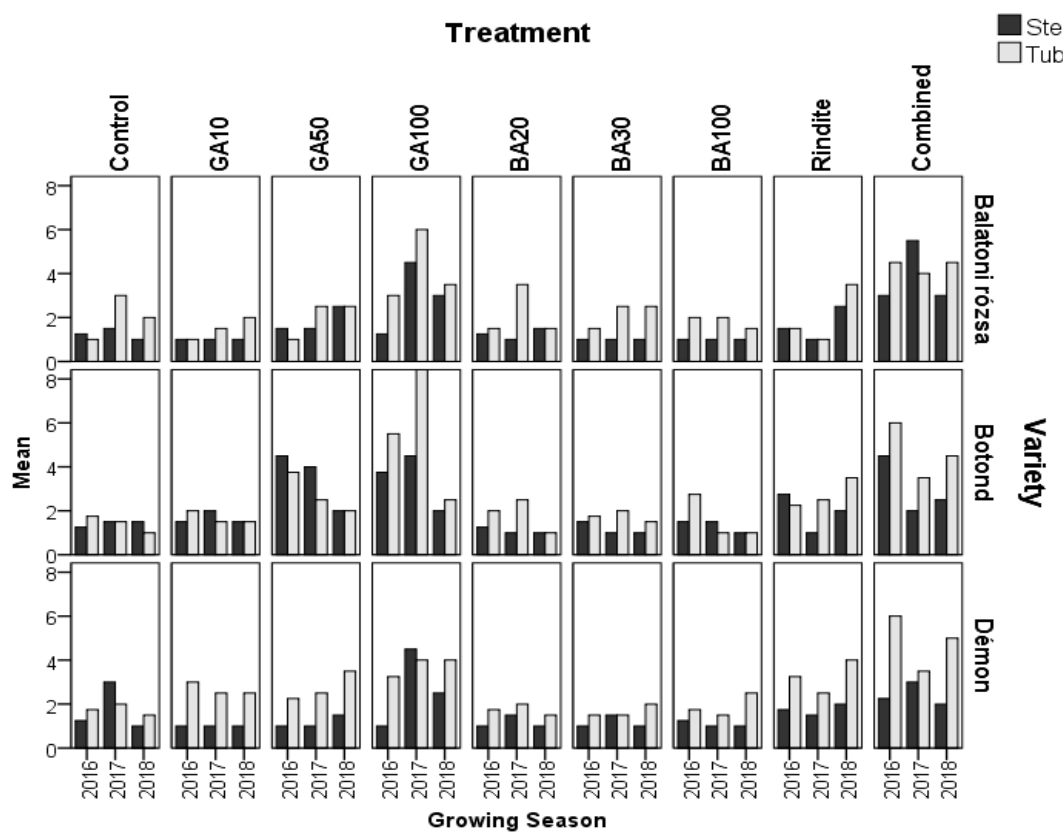

Figure 3

Effect of chemical treatments on the stem and tuber numbers of the investigated varieties

\section{DISCUSSION}

Our results confirmed that the chemical treatments significantly influenced the length of dormancy period, the stem and tuber number of the examined varieties.

According to our results, different chemical treatments significantly influenced the dormancy period, stem number and tuber setting of the varieties. According to our observations, there is a correlation between the efficiency of breaking dormancy, the number of stems and the number of developed tubers. This finding was also statistically proven by Duncan test. The GA50, GA100, Rindite and Combined treatments not only significantly reduced dormancy, but also increased the stem and tuber numbers of the examined varieties. This result is in agreement with findings of Wróbel et al. (2017). They found that GA was effective both for dormancy breaking and in promoting sprout growth. However, they used spherical tuber slices, each containing a single eye, so the sprouting of lateral buds and thus the change in stem number were different 
from that of whole tubers. According to they method, multiple sprouting was not possible. The consistence of the chemical treatments was also different. 1 ppm GA was used and only for 15 minutes, so the GA concentration is negligible compared to the experiments we performed. However, several combinations were used, $0.5-4 \%$ ethanol + GA and ethanol + GA + kinetin, respectively.

According to the regression analysis we did not find a linear relationship, so the change in dormancy due to the treatments only partially explains the change in stem and tuber number. Based on correlation analysis, the relationship is medium and inverse, so the effective the dormancy period shortening is, the higher the number of stems and tubers ( $\mathrm{r}=-0.46$, Pearson correlation is significant at the 0.01 level). This relationship is probably due to the physiological age of the tubers, where it's generally known then in the case of older tubers the apical dominance is over and lateral buds also start to germinate. The dormancy breaking treatments mimic the natural ageing of tubers.

GA100 and Combined treatments were the most effective for increasing the number of stems and tubers. GA100 increased the stem number by an average of $204.1 \%$ and the number of tubers by $259.9 \%$. While Combined treatment increased the stem number by an average of $209.5 \%$ and number of tubers by $268.0 \%$, compared to controls. According to our results, the combined effects of GA100 and Rindite on breaking dormancy are added together only to a small extent. In this approach, Rindite is the dominant component of the Combined treatment and therefore GA should not be used to break the tuber dormancy in this combination. However GA100 significantly and greatly increased the tuber number of plants developed from treated tubers. Its effect has been added to that of Rindite, so use of GA is advantageous to increase seed potato production. This result is in agreement with findings of Hassani et al. (2014). Based on their results, the use of GA not only shortens the days to sprouting but also increases the number of stems per tuber. Therefore application of GA is advisable in practice. They used mini-tubers for three hours by 50 ppm GA.

GA at 10 ppm and BA treatments did not result statistically justifiable reduction in dormancy and their application did not result in significant changes in stem and tuber number. Therefore their use to break dormancy or increase the tuber yield in tested concentrations is not advised. This observation is in contrast to results of Majeed and Bano (2006). They found that BA significantly shortened dormancy period, enhanced sprouting, increased stolon and tuber formation. However, it has been observed that the varieties have reacted differently to the treatments, so chemical treatments need to be adapted to the varieties. Probably the varieties we examined are less sensitive to BA treatments. 
Numbers of stems were significantly increased in 2016 by Combined, in 2017 by GA100, in 2018 by both treatments and by Rindite also. The number of tubers was significantly increased in each growing season by Combined and GA100 and in 2018 by Rindite too. Rindite significantly reduced dormancy during each growing season, but did not resulted in more stems and tubers, except in 2018.

We found a moderately strong correlation between the change of the tuber number and the stem number due to the treatments $(\mathrm{r}=0.572$, Pearson correlation is significant at the 0.01 level). In 2016, Combined treatment produced the highest stem number, and the same treatment resulted in the most tubers too. In 2017, GA100 had the greatest impact on the stem and tuber number increase. Combined treatment did not increase significantly the stem number of all varieties this year, but it increased the tuber number. In order to better understand the differences between treatments, varieties and growing seasons, further examinations are needed.

According to our results, Rindite and gibberellic-acid have an important role not only in breaking dormancy but also in increasing the number of tubers, which can be beneficial for the production of seed tubers. However, the treatments should be fine-tuned and adapted to the varieties, as they may respond differently to the treatments. It is hoped that incorporation of optimal treatment to varieties' production technology will not only solve the problem of dormancy breaking, but it can increase tuber setting per plants, too.

Author Contribution: Both authors contributed to the study conception and design. Material preparation, data collection and analysis were performed by Ádám Esztergályos. The first draft of the manuscript was written by Ádám Esztergályos, while Zsolt Polgár commented it critically. Authors revised and prepared the final version together. Both authors read and approved the final manuscript.

Compliance with Ethical Standards: Conflict of Interest: The authors declare that they have no conflict of interest. Statement of Human and Animal Right: This article does not contain any studies with human or animal subjects performed by any of the authors.

\section{REFERENCES}

Aksenova N.P., Konstantinova T.N., Golyanovskaya S.A., Sergeeva L.I., Romanov G.A. (2012). Hormonal Regulation of Tuber Formation in Potato Plants. Russ J Plant Physiol., 59(4), 451-466. DOI: $\underline{10.1134 / s 1021443712040024}$ 
Aksenova N.P., Sergeeva L.I., Konstantinova T.N., Golyanovskaya S.A., Kolachevskaya O.O., Romanov G.A. (2013). Regulation of potato tuber dormancy and sprouting. Russ J Plant Physiol., 60(3), 301-312. DOI: $10.1134 / s 1021443713030023$

Alexopoulos A.A., Aivalakis G., Akoumianakis K.A., Passam H.C. (2009). Bromoethane induces dormancy breakage and metabolic changes in tubers derived from true potato seed. Postharvest Biology and Technology, 54(3), 165-171. DOI: 10.1016/j.postharvbio.2009.07.004

Bamberg J. (2010). Tuber dormancy lasting eight years in the wild potato Solanum jamesii. Am J Potato Res., 87(2), 226-228. DOI: 10.1007/s12230-009-9124-9

Benkeblia N., Alexopoulos A.A., Passam H.C. (2008). Physiological and biochemical regulation of dormancy and sprouting in potato tubers (Solanum tuberosum L.). Fruit, Vegetable and Cereal Science and Biotechnology, 2, 54-68.

Beukema H.P., van der Zaag D.E. (1979). Dormancy and sprout growth. In: Potato improvement: Some factors and facts. International Agricultural Centre, Wageningen, 26-36.

Bryan J.E. (1989). Breaking dormancy of potato tubers. CIP Research Guide 16. International Potato Center, Lima, 6-9.

Burton W.G. (1989). Dormancy and sprout growth. In: The potato, 3rd edn. Longman Scientific \& Technical, Essex, 470-504.

Carli C., Mihovilovich E., Bonierbale M. (2016). Procedures for standard evaluation and data management of advanced potato clones. Module 4: Assessment of dormancy and sprouting behavior of elite and advanced clones. International Potato Center, pp 31. Link

Choudhuri H.C., Ghose S. (1963). Effect of gibberellic acid on sprouting, growth of internodes, tuber shape and yield in different varieties of potatoes. Europ. Potato J., 6(3), 160-167. DOI: $\underline{10.1007 / b f 02365783}$

Coleman W.K. (1983). An evaluation of bromoethane for breaking tuber dormancy in Solanum tuberosum L. American Potato Journal, 60(3), 161-167. DOI: $10.1007 / b f 02853997$

Coleman W.K., Donnelly D.J., Coleman S.E. (2001). Potato microtubers as research tools: A review. Am. J. Pot Res., 78(1), 47-55. DOI: 10.1007/bf02874824

Ezekiel R., Singh B. (2003). Influence of relative humidity on weight loss in potato tubers stored at high temperatures. Indian Journal of Plant Physiology, 8(2), 141-144.

Fernie A.R., Willmitzer L. (2001). Molecular and Biochemical triggers of potato tuber development. Plant Physiology, 127(4), 1459-1465. DOI: $\underline{10.1104 / p p .010764}$

Hartmann A., Senning M., Hedden P., Sonnewald U., Sonnewald S. (2011). Reactivation of meristem activity and sprout growth in potato tubers require both cytokinin and gibberelin. Plant Physiology, 155(2), 776-796. DOI: $\underline{10.1104 / p p .110 .168252}$

Hassani F., Zareian A., Rezvani E. (2014). Effects of chemical treatments on dormancy breaking and some sprouting characteristics of two potato cultivars in different tuber sizes. European Journal of Experimental Biology, 4(4), 98-102. Link

Hemberg T. (1985). Potato rest. In: Li PH (ed) Potato Physiology. Academic Press, New York, 353-388.

Hosseini M.B., Afshari R.T., Salimi K. (2011). Breaking dormancy of potato minitubers with thiourea. Potato J., 38(1), 9-12.

Majeed A., Bano A. (2006). Role of growth promoting substances in breaking potato (Solanum tuberosum L.) tuber dormancy. Journal of Agriculture and Social Sciences, 2(3), 175-178.

Muthoni J., Kabira J., Shimelis H., Melis R. (2014). Regulation of potato tuber dormancy: A review. Australian Journal of Crop Science, 8(5), 754-759.

Nasiruddin M., Khatun R., Haydar F.M.A., Imtiaj A., Alam M.F. (2016). Effect of physical and chemical treatments on sprouting of dormant potato tubers. Plant Environment Development, 5(2), 24-27.

Pavlista A.D. (2004). Physiological Aging of Seed Tubers. Nebraska Potato Eyes, 16, 1-4. 
Struik P.C., Lommen W.J.M. (1999). Improving the field performance of micro and mini-tubers. Potato Res., 42, 559-568. DOI: $\underline{10.1007 / b f 02358172}$

Struik P.C., Wiersema S.G. (1999). Seed potato technology. Wageningen Academic Publishers, Wageningen, 95-134. DOI: 10.3920/978-90-8686-759-2

Suttle J.C. (2004). Physiological regulation of potato tuber dormancy. American Journal of Potato Research, 81(4), 253-262. DOI: $10.1007 / b f 02871767$

Suttle J.C. (2007). Dormancy and sprouting. In: Vreugdenhil D (ed) Potato biology and biotechnology: Advances and perspectives. Elsevier, Amsterdam, 287-309. DOI: 10.1016/b978-0444510181/50056-7

Suttle J.C. (2008). Effects of synthetic phenylurea and nitroguanidine cytokinins on dormancy break and sprout growth in Russet Burbank minitubers. Am. J. Pot Res., 85(2), 121-128. DOI: $\underline{10.1007 / s 12230-008-9002-x}$

Tiemens-Hulscher, M., Delleman, J., Eisinger, E., Lammerts Van Bueren, E. (2013). Potato breeding: a practical manual for the potato chain. (Potato world magazine). Aardappelwereld BV., The Hague, pp 148.

Tor J.J. (2011). Influence of temperature and day-length on dormancy in seed potato cv. 'Asterix'. The European Journal of Plant Science and Biotechnology, 5, 55-61.

Van Ittersum M.K. (1992). Variation in the duration of tuber dormancy within a seed potato lot. Potato Res., 35(3), 261-269. DOI: $10.1007 /$ bf02357706

Wiersema S.G. (1985). Physiological development of potato seed tubers. International Potato Center, Lima, pp 16.

Wiltshire J.J.J., Cobb A.H. (1996). A review of the physiology of potato tuber dormancy. Annals of Applied Biology, 129(3), 553-569. DOI: 10.1111/j.1744-7348.1996.tb05776.X

Wróbel S. (2008). Early dormancy breaking of tubers in fast virus diagnostic for new potato cultivars. Progress in Plant Protection, 48, 552-555.

Wróbel S., Kęsy J., Treder K. (2017). Effect of growth regulators and ethanol on termination of dormancy in potato tubers. American Journal of Potato Research, 94(5), 544-555. DOI: 10.1007/s12230-017$\underline{9592-2}$

Zarzyńska K. (2004). The length of tuber dormancy period in new potato cultivars. Biuletyn IHAR 232, 5-14.

(C) Copyright 2020 by the authors. This is an open access article under the terms and conditions of the Creative Commons attribution (CC-BY-NC-ND) license 4.0. 